\title{
Editorial
}

\section{Hot Topics in Macromolecular Science}

\author{
Ana Maria Díez-Pascual
}

Citation: Díez-Pascual, A.M. Hot Topics in Macromolecular Science. Macromol 2021, 1, 173-176.

https://doi.org/10.3390/ macromol1030013

Received: 14 June 2021

Accepted: 17 June 2021

Published: 23 June 2021

Publisher's Note: MDPI stays neutral with regard to jurisdictional claims in published maps and institutional affiliations.

Copyright: (C) 2021 by the author. Licensee MDPI, Basel, Switzerland. This article is an open access article distributed under the terms and conditions of the Creative Commons Attribution (CC BY) license (https:// creativecommons.org/licenses/by/ $4.0 /)$.
Universidad de Alcalá, Facultad de Ciencias, Departamento de Química Analítica, Química Física e Ingeniería Química, Ctra. Madrid-Barcelona, Km. 33.6, 28805 Alcalá de Henares, Madrid, España (Spain); am.diez@uah.es; Tel.: +34-918-856-430

In these first two issues of the new open access Journal Macromol [1]-A Journal of Macromolecular Research-several interesting articles were accepted after a rigorous peer-review process, in which current topics in the field of Macromolecular Science are discussed. A few reviews have been published that show the importance that diverse families of polymeric materials have in a wide range of applications, and how structural variations can condition the macroscopic properties. In particular, polysiloxane-based polymers have been used in applications that range from food production to cosmetics and surfactants [2]. Due to the hydrophobic nature of the polysiloxane backbone and its cationic-anionic regions, ionomers and polyelectrolytes have been shown to exhibit antimicrobial and antifugal properties, working similarly to detergents with hydrophobic and hydrophilic regions. More recent applications of this polymeric family are in energy storage and conversion, since they have low glass transition temperatures that favor ion conductivity and are considered highly flexible. Future uses include fields that exploit their intrinsic tenability (backbone flexibility, hydrophobicity, charge content and type), such as shape memory, self-healing and adhesive films.

On the other hand, self-healing polymers have received significant attention in paint, coating, adhesives and other industries, as well as in academia, due to their ability to extend materials' service life, enhancing protection, and guaranteeing sustainability. Noticeable progress has been recently attained in the preparation and properties of intrinsic selfhealing materials, based on H-bonding interactions [3]. This interaction is highly versatile and advantageous for the manufacture of transparent self-healing coatings capable of undergoing multiple healing cycles within a moderate temperature range. Future work on self-healing polymers should focus on (a) improving mechanical properties, (b) fast selfhealing performance at moderate temperature, (c) achieving macro-damage repair under severe weathering conditions, $(\mathrm{d})$ incorporating self-healing properties into multifunctional materials, such as antibacterial, anticorrosion, and transparent coatings for optoelectronics and other applications.

Chitosan (CS), the second most abundant biopolymer in nature after cellulose, is a promising material due to its outstanding properties, such as biodegradability, biocompatibility, and antimicrobial action, as well as for its adsorption capacity, given that its cationic character enables its interaction with other molecules. The use of CS for the synthesis of adsorbent composites, due to its increased adsorption abilities, is a very hot topic nowadays [4]. The high adsorption capacities of CS derivatives are ascribed to the grafting process and cross-linking reactions in order to link unit chains (each with other) with macromolecular structures. The efficiency of the adsorption process depends on a large number of parameters, including the compound molecular weight, degree of dilution, functional groups, temperature, $\mathrm{pH}$, etc. CS-based materials are very promising for the removal of a wide variety of pharmaceutical compounds (i.d. tetracycline, pramipexole, dorzolamide, diclofenac, furosemide, etc.) and personal care products (Ketoprofen, Ibuprofen, Benzoin acid, etc.) from aqueous solutions and, in the near future, are likely to be used for numerous adsorption applications. 
Another hot topic is polyelectrolytes (PE), which are the focus of much interdisciplinary research. In the field of polymer science and soft matter, they provided the dimensions of electrostatic interactions, which opens up a huge variety of opportunities for new physical properties and applications $[5,6]$. PE shows a comprehensive range of structures that stretch from simple hydrophilic homopolyelectrolytes to proteins with a $\mathrm{pH}$-dependent charge patch and hydropathic heterogeneity. Such variety enables the development of multifunctional nanostructures with wonderful possibilities for biomedical applications, in particular, in pharmaceutical science, drug delivery and tissue engineering.

The other current topic is in the field of polymer nanocomposites. In this regard, a lot of articles in the last decade have been devoted to polymeric nanocomposites incorporating nanoscale fillers [7]. One of the most important is carbon nanomaterials, such as carbon nanotubes (CNTs), which possess a large aspect ratio, low mass density, and unique chemical, physical, and electronic properties that provide exciting possibilities for nanoscale applications. However, two matters should be considered when dealing with this type of nanomaterial: their strong agglomerating tendency and the metallic impurities and carbonaceous fragments that go along with the CNTs. The successful utilization of CNTs in a wide variety of applications, in particular, in the field of polymer composites, is based on their uniform dispersion and the development of a strong chemical interaction with the polymeric matrix [8,9]. To achieve these aims, different approaches to CNT modification using polymers have been reported, including the covalent functionalization via "grafting to" or "grafting from" strategies. The resulting polymer-grafted CNTs have applications as biosensors, membranes, energy storage substances, and EMI shielding.

Polyethylene oxide (PEO) hydrogels are biocompatible materials, widely used in wound healing, drug delivery, and tissue engineering [10]. PEO can be combined with other polymers to create multifunctional systems, such as using heparin-peptide interactions for the formation of bioactive noncovalent networks and carboxymethyl cellulose to create hydrogel films with potential in tissue engineering [11]. Adaptable crosslinking procedures are very important for the development of novel multifunctional platforms for the loading and release of biomacromolecules. In this regard, crosslinking with peroxides provides the possibility of reaction in the melt state, and has been successfully used to synthesize soft hydrogels which enable the controlled release of proteins such as serum albumin (BSA) and lysozyme (LYZ) [12].

Poly(L-lactic acid) (PLLA) is a biobased aliphatic polyester, which possesses excellent thermomechanical properties, and has great potential in packaging, biomedical, agriculture, automotive, textiles, electronics, construction, and single used items [13]. To improve on its properties, blending with other polymers or the incorporation of nanofillers is pursued [14]. To achieve effective antimicrobial activity for smart packaging applications, micro/nano 3D micropillars decorated with cone- and needle-shaped nanostructures were implemented on the surface of $\mathrm{PLLA} / \mathrm{SiO}_{2}$ nanocomposite films by means of thermal nanoimprint lithography, a novel and feasible fabrication technique with multiple industrial applications [15].

Poly(ethylene succinate) (PES) is another biodegradable aliphatic polyester, showing similar physical properties to those of polyethylene and polypropylene [16]. Many researchers have investigated the properties of PES, including crystal structure, crystallization, morphology, melting behavior, and enzymatic degradation. To meet various practical application requirements, some PES-based copolymers were further designed and synthesized. In this regard, PES-based composites incorporating cyanuric acid (CA), one of the most efficient nucleating agents for some biodegradable polyesters, were prepared via solution casting method [17], and its crystallization rate was noticeably enhanced, which is interesting from the perspective of polymer processing.

Another special type of polymer, known as covalent organic frameworks (COFs), has recently drawn great attention. COFs are crystalline porous polymer frameworks with well-defined, high-order structures, attributed to the "self-templated" polymerization, in which the initial molecular structure provides specific sites to guide the subsequent 
monomers into place, allowing the polymer chain to extend over a 3D frame with an aligned arrangement [18]. COFs possess numerous advantages including a large surface area, high porosity, tunable composition, and designable dimension of molecular skeleton and pores. To synthesize COFs, the building blocks, mainly the monomers with $\pi$-backbones and rigid conformations, are connected through boronate-ester, imine, $\mathrm{C}=\mathrm{C}$, and other linkages under mild conditions, resulting in a facile method of preparing COFs as precursors for porous carbon production [19].

Recently, vegetable oils have been used as precursors for polymeric materials. They are aliphatic in nature, with significant chain flexibility, providing a generally soft and not very strong material, even at a relatively high crosslinking density. The epoxidation of oils and fatty acids has been studied, with the aim of using them in practical applications, including tissue engineering [20], antimicrobial coatings [21] and wound healing [22]. Vegetable oils, complexed with cyclodextrins, can be regarded as a novel therapeutic option in treatments involving painful processes and in the development of new antinociceptive agents, due to an improved bioavailability associated with solubility, dissolution, and permeability, as well as the reduction in doses and the side effects [23]. On the other hand, hyperbranched, low-molecular-weight polyethylene oils were synthesized using $\mathrm{Ni}$ (II) complexes bearing aryliminopyridine ligands, and it was found that the degree of branching and the molecular weight of the produced samples were hardly sensitive to the reaction conditions [24].

Funding: This research received no external funding.

Conflicts of Interest: The authors declare no conflict of interest.

\section{References}

1. Díez-Pascual, A.M. Macromol-A Journal of Macromolecular Research-Open Access Journal. Macromol 2021, 1, 1. [CrossRef]

2. Poon, L.; Hum, J.R.; Weiss, R.G. Neat Linear Polysiloxane-Based Ionic Polymers: Insights into Structure-Based Property Modifications and Applications. Macromol 2021, 1, 2-17. [CrossRef]

3. Gadwal, I. A Brief Overview on Preparation of Self-Healing Polymers and Coatings via Hydrogen Bonding Interactions. Macromol 2021, 1, 18-36. [CrossRef]

4. Liakos, E.V.; Lazaridou, M.; Michailidou, G.; Koumentakou, I.; Lambropoulou, D.A.; Bikiaris, D.N.; Kyzas, G.Z. Chitosan Adsorbent Derivatives for Pharmaceuticals Removal from Effluents: A Review. Macromol 2021, 1, 130-154. [CrossRef]

5. Papagiannopoulos, A. Current Research on Polyelectrolyte Nanostructures: From Molecular Interactions to Biomedical Applications. Macromol 2021, 1, 155-172. [CrossRef]

6. Díez-Pascual, A.M.; Shuttleworth, P.S. Layer-by-Layer Assembly of Biopolyelectrolytes onto Thermo/pH-Responsive Micro/Nano-Gels. Materials 2014, 7, 7472-7512. [CrossRef] [PubMed]

7. Díez-Pascual, A.M. Chemical Functionalization of Carbon Nanotubes with Polymers: A Brief Overview. Macromol 2021, 1, 64-83. [CrossRef]

8. Díez-Pascual, A.M.; Naffakh, M. Grafting of an aminated poly(phenylene sulphide) derivative to functionalized single-walled carbon nanotubes. Carbon 2012, 50, 857-868. [CrossRef]

9. Diez-Pascual, A.M.; Martinez, G.; Gonzalez-Dominguez, J.M.; Martinez, T.; Gomez-Faou, M.A. Grafting of a hydroxylated PEEK derivative to the surface of single-walled carbon nanotubes. J. Mater. Chem. 2010, 20, 8285-8296. [CrossRef]

10. D'souza, A.A.; Shegokar, R. Polyethylene glycol (PEG): A versatile polymer for pharmaceutical applications. Expert Opin. Drug Deliv. 2016, 13, 1257-1275. [CrossRef] [PubMed]

11. Lee, S.Y.; Bang, S.; Kim, S.; Jo, S.Y.; Kim, B.-C.; Hwang, Y.; Noh, I. Synthesis and in vitro characterizations of porous carboxymethyl cellulose-poly(ethylene oxide) hydrogel film. Biomater. Res. 2015, 19, 12. [CrossRef]

12. Papagiannopoulos, A.; Vlassi, E.; Pispas, S.; Tsitsilianis, C.; Radulescu, A. Polyethylene Oxide Hydrogels Crosslinked by Peroxide for the Controlled Release of Proteins. Macromol 2021, 1, 37-48. [CrossRef]

13. Balla, E.; Daniilidis, V.; Karlioti, G.; Kalamas, T.; Stefanidou, M.; Bikiaris, N.D.; Vlachopoulos, A.; Koumentakou, I.; Bikiaris, D.N. Poly(lactic Acid): A Versatile Biobased Polymer for the Future with Multifunctional Properties-From Monomer Synthesis, Polymerization Techniques and Molecular Weight Increase to PLA Applications. Polymers 2021, 13, 1822. [CrossRef]

14. Naffakh, M.; Diez-Pascual, A.M.; Marco, C. Polymer blend nanocomposites based on poly(l-lactic acid), polypropylene and WS2 inorganic nanotubes. RSC Adv. 2016, 6, 40033-40044. [CrossRef]

15. Psochia, E.; Papadopoulos, L.; Gkiliopoulos, D.J.; Francone, A.; Grigora, M.-E.; Tzetzis, D.; de Castro, J.V.; Neves, N.M.; Triantafyllidis, K.S.; Torres, C.M.S.; et al. Bottom-Up Development of Nanoimprinted PLLA Composite Films with Enhanced Antibacterial Properties for Smart Packaging Applications. Macromol 2021, 1, 49-63. [CrossRef]

16. Gan, Z.; Abe, H.; Doi, Y. Biodegradable Poly(ethylene succinate) (PES). 1. Crystal Growth Kinetics and Morphology. Biomacromolecules 2000, 1, 704-712. [CrossRef] [PubMed] 
17. Zhang, K.; Qiu, Z. Effect of Cyanuric Acid as an Efficient Nucleating Agent on the Crystallization of Novel Biodegradable Branched Poly(Ethylene Succinate). Macromol 2021, 1, 112-120. [CrossRef]

18. Geng, K.; He, T.; Liu, R.; Dalapati, S.; Tan, K.T.; Li, Z.; Tao, S.; Gong, Y.; Jiang, Q.; Jiang, D. Covalent organic frameworks: Design, synthesis, and functions. Chem. Rev. 2020, 120, 8814-8933. [CrossRef]

19. Yu, X.; Zheng, T.; Pilla, S. Polymer-Derived Nitrogen-Doped Carbon Nanosheet Cluster and Its Application for Water Purification. Macromol 2021, 1, 84-93. [CrossRef]

20. Diez-Pascual, A.M.; Diez-Vicente, A.L. Epoxidized Soybean Oil/ZnO Biocomposites for Soft Tissue Applications: Preparation and Characterization. ACS Appl. Mater. Interfaces 2014, 6, 17277-17288. [CrossRef] [PubMed]

21. Diez-Pascual, A.M.; Diez-Vicente, A.L. Development of Linseed Oil/TiO2 Green Nanocomposites as Antimicrobial Coatings. J. Mater. Chem. B 2015, 3, 4458-4471. [CrossRef] [PubMed]

22. Diez-Pascual, A.M.; Diez-Vicente, A.L. Wound Healing Bionanocomposites Based on Castor Oil Polymeric Films Reinforced with Chitosan-Modified ZnO Nanoparticles. Biomacromolecules 2015, 16, 2631-2644. [CrossRef] [PubMed]

23. Oliveira Brito Pereira Bezerra Martins, A.; Correia de Oliveira, M.R.; Alcântara, I.S.; Rodrigues, L.B.; Cesário, F.R.A.S.; da Silva, M.S.A.; Castro, F.F.; Nascimento, E.P.; Albuquerque, T.R.; Quintans Júnior, L.J.; et al. Effect of the Croton rhamnifolioides Essential Oil and the Inclusion Complex (OEFC/ $\beta-\mathrm{CD})$ in Antinociceptive Animal Models. Macromol 2021, 1, 94-111. [CrossRef]

24. D'Auria, I.; Saki, Z.; Pellecchia, C. Iminopyridine Ni(II) Catalysts Affording Oily Hyperbranched Ethylene Oligomers and/or Crystalline Polyethylenes Depending on the Reaction Conditions: Possible Role of In Situ Catalyst Structure Modifications. Macromol 2021, 1, 121-129. [CrossRef] 